\title{
Quince años después: traducciones legales, globalización del plea bargaining y americanización del proceso penal
}

Fifteen Years After: Legal Translations,
Globalization of Plea Bargaining and
Americanization of Criminal Procedure

Máximo Langer*

Recepción: 19/04/19

Aceptación: 22/04/19

Recepción y aceptación final: 22/04/19

Resumen: el texto responde a las observaciones realizadas por Bachmaier, Engländer y Correa Robles al artículo principal de esta discusión.

Palabras clave: reconceptualización, metáfora de la traducción, proceso penal alemán

\begin{abstract}
Bachmaier, Engländer and Correa Robles on Langer's main paper.

Keywords: reconceptualization, metaphor of translation, German criminal procedural law
\end{abstract}

* Catedrático de Derecho Penal, Derecho Procesal Penal y Derecho Penal Internacional de la Facultad de Derecho de la Universidad de California, Los Ángeles; Doctor en Ciencias Jurídicas, Universidad de Harvard; Abogado, Universidad de Buenos Aires. Correo electrónico: langer@law.ucla.edu 


\section{Introducción}

Quiero comenzar agradeciendo a Antonella Donnes, Hernán Bouvier y la Revista Discusiones por dar lugar al intercambio sobre mi artículo originalmente publicado en inglés como "From Legal Transplants to Legal Translations: The Globalization of Plea Bargaining and the Americanization Thesis in Criminal Procedure" en Harvard International Law Journal en el año 2004. Muchas gracias también a Lucas Tassara por haber traducido el artículo del inglés al español. Quiero también agradecer especialmente a los distinguidos Prof. Dra. Lorena Bachmaier, Prof. Dr. Carlos Correa Robles y Prof. Dr. Armin Engländer por haberme hecho el honor de escribir sus importantes y generosas contribuciones sobre mi trabajo en este volumen.

Este es un trabajo especial para mí porque fue el primer artículo que publiqué en inglés y, como tal, fue mi carta de presentación ante la academia legal estadounidense en particular y de habla inglesa más en general. Es una especial satisfacción para mí que el artículo esté ahora siendo publicado por primera vez en español, mi idioma natal y en el que me formé inicialmente como jurista en Argentina ${ }^{1}$.

Los quince años que han pasado desde la publicación de este artículo y las contribuciones para este número de los profesores Bachmaier, Correa Robles y Engländer me dan una oportunidad para reflexionar sobre cómo y en qué medida los aportes de este trabajo han resistido el paso del tiempo. Para hacer este análisis, es necesario describir sus principales contribuciones.

1 El artículo también ha sido traducido al chino por Cheng Lei y publicado como 从法律移 植到法律翻译：辩诉交易的全球化和刑事诉讼的美国化, China Procuratorate, Junio 2005; y al portugués por Ricardo Jacobsen Gloeckner y publicado como “Dos Transplantes Jurídicos às Traduções Jurídicas: a Globalizaçõa do Plea Bargaining e a Tese da Americanizaçõo do Processo Penal", Delictae, 2, 2017. La versión original en inglés también ha sido reproducida en Thaman, S. (comp.), World Plea Bargaining: Consensual Procedures and the Avoidance of the Full Criminal Trial, Durham, Carolina Academic Press, 2010, pp. 3-80; y en Parisi, F., Ginsburg, T. y Monateri, P.G. (comps.), Classics in Comparative Law, Cheltenham, Edward Elgar, 2014. 
Quince años después: traducciones legales, globalización del plea bargaining...

\section{Proceso penal, americanización y los sistemas acusa- torio e inquisitivo}

Una primera aspiración de este trabajo fue incluir al proceso penal como un tema de estudio importante y fértil para el análisis y la literatura sobre americanización y globalización del derecho. El argumento principal del artículo dentro de este espacio es que, si bien la influencia del proceso acusatorio estadounidense en general y del plea bargaining estadounidense en particular sobre los procesos penales continentales europeos y latinoamericanos es clara, esta influencia no ha resultado en una americanización en sentido fuerte de estos procesos, sino en una fragmentación de los procesos penales de la tradición continental europea y latinoamericana.

Para decirlo más concretamente, el proceso acusatorio estadounidense tiende a concebir al proceso penal como una disputa entre dos partes frente a un tribunal pasivo, mientras que las jurisdicciones de la tradición continental europea y latinoamericana han tendido a concebir al proceso penal como una investigación oficial única llevada a cabo por funcionarios imparciales. El argumento del artículo es que la influencia estadounidense no ha resultado en la simple adopción y predominio del proceso penal como una disputa en las jurisdicciones de la tradición continental europea y latinoamericana. Por el contrario, esta influencia estadounidense ha contribuido a fragmentar esta tradición en la medida en que algunas de sus jurisdicciones todavía predominantemente conciben el proceso penal como una investigación oficial, mientras que en otras el modelo de la disputa se ha vuelto más relevante en diferentes grados y niveles, y todavía en otras han aparecido otros modelos distintos de los dos mencionados.

Este argumento y análisis han resistido bien el paso del tiempo ${ }^{2}$. En su contribución, Correa Robles expresa su acuerdo con él en su análisis sobre la introducción de mecanismos consensuales en Alemania y Chile 3 . Pero

2 Para usos de este análisis en la literatura, ver, por ejemplo, Armenta Deu, T., Sistemas procesales penales: La justicia penal en Europa y América, Madrid, Marcial Pons, 2012, p. 288.

3 Correa Robles, C., "Mecanismos negociados de resolución de conflictos penales en Chile y Alemania -Una aproximación pragmática”, en este volumen de Discusiones, sección 9: "El fenómeno descrito muestra ... una creciente fragmentación del proceso penal...”. Las contribuciones a este volumen también discuten la tesis de la americanización en sentido débil 
más allá de las contribuciones a este número de Discusiones, para ilustrar la validez de este argumento uno puede comparar, por ejemplo, los procesos penales de Chile, Colombia, y la provincia de Buenos Aires. Estas tres jurisdicciones seguían modelos procesales penales escritos y el modelo de la investigación oficial antes de la adopción de reformas acusatorias que incluyeron formas consensuales para llegar a una condena como el procedimiento abreviado. Sin embargo, estas tres jurisdicciones no han adoptado en igual medida un modelo de la disputa que parece ser más predominante en Chile que en las otras dos jurisdicciones, y que parece ser más predominante en Colombia, al menos en términos de su Código de Procedimiento Penal, que en la Provincia de Buenos Aires.

Esta fragmentación también puede observarse en Europa si uno compara, por ejemplo, los procesos penales de Alemania e Italia ya que, con la adopción de sus reformas acusatorias, esta última se ha acercado más a un modelo de la disputa que la primera. Entretanto, la práctica de los entendimientos o acuerdos en Alemania ha llevado al avance en esa jurisdicción de un modelo que, como otra contribución del artículo en discusión, identifiqué y denominé el "modelo del juez-gerente basado en la cooperación”. Bajo este tercer modelo, que discutiré en más detalle más adelante, el rol del tribunal no es ni el de un árbitro pasivo ni el de un investigador activo de la verdad material, sino el dar una respuesta rápida a los casos penales.

que defiendo en el artículo central de esta discusión y que es parte de mi argumento más general sobre la fragmentación de la concepción del proceso penal en la tradición jurídica continental-europea y latinoamericana. Bachmaier está de acuerdo con esta caracterización de americanización en sentido débil al decir que, como "Langer pone de relieve, la importación de fórmulas de consenso en Europa puede calificarse como una americanización 'débil"'. Véase Bachmaier, L. "La no-americanización del proceso penal continental europeo: Del trasplante a la traducción jurídica en Langer" en este volumen de Discusiones. Correa Robles, también parece referirse a ella cuando dice que, "como correctamente se desprende del artículo de Langer, tanto la modificación legal introducida a la StPO hace 10 años, y que consagró formalmente los Absprachen en dicho ordenamiento, como el reconocimiento del procedimiento abreviado en Chile, no han 'americanizado' mayormente el proceso penal alemán ni el chileno". Dejo para la sección 6 de este trabajo el análisis de los comentarios de Engländer sobre la tesis de americanización en sentido débil en Alemania. 
Quince años después: traducciones legales, globalización del plea bargaining...

\section{Reconceptualización de los sistemas acusatorio e inquisitivo}

Otra contribución del artículo fue articular una nueva conceptualización de los sistemas acusatorio e inquisitivo para poder analizar el fenómeno de la influencia del proceso penal estadounidense sobre otros sistemas. Esta nueva conceptualización distingue, en primer lugar, entre las estructuras de interpretación y sentido acusatoria e inquisitiva como dos formas de entender cómo investigar, perseguir y juzgar casos penales, y la dimensión de disposiciones internas que se refiere a la internalización de distintas concepciones del proceso penal por parte de actores individuales. El trabajo desarrolló estos conceptos para darle un contenido concreto a lo que pueden denominarse las culturas acusatorias e inquisitivas y para explicar cómo pueden reproducirse y cambiar en el tiempo.

También como parte de su nueva conceptualización de los sistemas acusatorio e inquisitivo, el trabajo articuló la dimensión de poderes procesales como una forma de identificar cómo los poderes y responsabilidades que distintos actores e instituciones del proceso penal tienen en distintos sistemas pueden contribuir a reproducir y cambiar sistemas procesales en el tiempo (identificando, por ejemplo, posibles focos de resistencia a reformas procesales que intentan quitarle poder a ciertos actores o instituciones).

El artículo luego utiliza estas herramientas teóricas para explicar por qué el plea bargaining o mecanismos similares fueron transformados o resistidos al ser adoptados en distintas jurisdicciones continentales europeas y latinoamericanas.

Las contribuciones a este número de Discusiones no discuten esta reconceptualización de los sistemas acusatorio e inquisitivo. Pero Correa Robles la utiliza en su contribución al mencionar recientes resistencias a ciertos cambios procesales en materia civil propuestos en Chile ${ }^{4}$. Esta reconceptualización también ha sido utilizada por distintos autores para analizar, por ejemplo, reformas procesales penales acusatorias en América

4 Correa Robles, C., op. cit., nota 51. 
Latina $^{5}$ e Italia ${ }^{6}$; posibles reformas legales o interpretaciones constitucionales en jurisdicciones de la tradición anglosajona inspiradas en la tradición continental-europea ${ }^{7}$; el proceso penal de los tribunales penales internacionales $^{8}$; y la internacionalización de la prueba en materia penal ${ }^{9}$.

\section{La metáfora de la traducción legal y la circulación de ideas legales entre sistemas jurídicos}

Otra contribución del artículo fue proponer la metáfora de la "traducción legal" como una herramienta heurística para referirse a la circulación de ideas, normas e instituciones legales entre sistemas jurídicos. Para comprender esta contribución es necesario explicar que, dentro de la literatura de derecho comparado, la circulación de ideas, normas e instituciones legales ha sido predominantemente referida como un "trasplante legal", metáfora que Alan Watson popularizó con su trabajo. El problema de la metáfora del "trasplante legal" es que sugiere que la idea, norma o institución legal original y la trasplantada son esencialmente iguales. Es decir, una planta o un órgano humano que es trasplantado de un ambiente o cuerpo a otro es esencialmente igual, aunque puede cambiar en cierta medida o ser rechazado por el ambiente o cuerpo receptor.

Pero al estudiar las múltiples variaciones de plea bargaining y otros mecanismos consensuales que permiten imponer una condena penal alre-

5 Ver, por ejemplo, Ciocchini, P., "Reformers' unfulfilled promises: accountability deficits in Argentinean criminal courts", International Journal of Law in Context, 14 (1), 2018, pp. 22-42, pág. 27.

6 Ver, por ejemplo, Montana, R., "Procedural tradition in the Italian Criminal Justice System: The Semi-adversarial Reform in 1989 and the inquisitorial cultural resistance to adversarial principles", The International Journal of Evidence \& Proof, 20 (4), 2016, pp. 289-304.

7 Roach, K., "Wrongful Convictions: Adversarial and Inquisitorial Themes", N.C.J. Int'l L. \& Com. Reg., 35 (2), 2010, pp. 387-446; Sklansky, D., "Anti-Inquisitorialism”, Harvard Law Review, 112, 2009, pp.1634-1704, pág. 1679.

8 Jackson, J.D. y Summers, S. J., The Internationalisation of Criminal Evidence: Beyond the Common Law and Civil Law Traditions, Cambridge University Press, 2012, pp. 129-130; Langer, M., "The Rise of Managerial Judging in International Criminal Law", American Journal of Comparative Law, 53 (4), 2005, pp. 835-909.

9 Jackson, J.D. y Summers, S.J., op. cit., pág. 388. 
Quince años después: traducciones legales, globalización del plea bargaining...

dedor del mundo, noté diferencias muy sustantivas entre ellos, ya sea por decisión de los redactores o usuarios de las regulaciones de estos mecanismos en distintos sistemas jurídicos o por diferencias sustanciales entre sistemas jurídicos. Fue por ello que propuse la metáfora de la "traducción legal" como una herramienta heurística alternativa para describir la circulación de ideas, normas, e instituciones legales entre sistemas jurídicos.

La metáfora sugiere que hay un proceso de traducción y que una institución como el plea bargaining puede transformarse sustancialmente al ser traducida a otro sistema jurídico sea por decisiones de los redactores, reformadores o usuarios (es decir, los traductores de la norma, según la metáfora) o por diferencias sustanciales entre el sistema jurídico receptor y el sistema jurídico original que pueden entenderse como dos "lenguajes".

Esta metáfora encaja especialmente bien con la reconceptualización de los sistemas acusatorio e inquisitivo ya descrita y también propuesta por mi artículo, ya que si estos sistemas son entendidos como dos estructuras de interpretación y sentido, la adopción de mecanismos consensuales de sistemas acusatorios a sistemas inquisitivos puede ser entendida como un proceso de traducción de una estructura acusatoria de interpretación y sentido o idioma a una estructura inquisitiva de interpretación y sentido o idioma.

Las contribuciones a este volumen discuten esta metáfora de la traducción en detalle e, interesantemente y sin saberlo los autores al momento de escribir sus artículos, están en un diálogo interesante entre ellos.

Por ejemplo, si bien Bachmaier en su sofisticado e informado análisis de este tema elogia la metáfora de la traducción legal ${ }^{10}$, señala que la metáfora del trasplante legal ya connota la posibilidad de cambios sustanciales entre la idea, norma o institución legal original y la trasplantada ${ }^{11}$. Mientras que Engländer contestándole sin saberlo a Bachmaier, coincide conmigo en este punto al decir que la ventaja de usar la metáfora de la traducción legal es que puede ser conectada con la filosofía del lenguaje y con los fenómenos de transformación, cambio y reinterpretación que yo describo

10 Bachmaier, dice que “el término elegido por Langer no puede ser más acertado”. Bachmaier, L., op. cit.

11 Ver Bachmaier, L., op. cit., nota 14 y texto principal que acompaña dicha nota y comienzo de la sección 6. 
en mi artículo" ${ }^{12}$. Correa Robles agrega que "la flexibilidad del concepto de traducción ... permite entender las características particulares generadas en cada sistema, como consecuencia de la interacción con las prácticas judiciales preexistentes..." ${ }^{\prime 3}$. Es también importante notar que mientras la metáfora del trasplante es una metáfora botánica o anatómica, la metáfora de la traducción es comunicativa. Esto no es menor ya que el derecho es por definición comunicativo.

A su vez, Engländer señala que la metáfora de la traducción tiene el riesgo de ser malentendida ya que una traducción es considerada ideal cuando el significado original es preservado en la mayor medida posible ${ }^{14}$. Mientras que como yo señalo en mi artículo refiriéndome a la literatura sobre estudios de traducción, Bachmaier explica con cita del Diccionario General de la Lengua Española, que el concepto de traducción tiene diversas acepciones que van "desde la más literal ("expresar en un idioma lo dicho o escrito originariamente en otro distinto") hasta la más amplia ("convertir o transformar una cosa en otra"), pasando por otra intermedia ("explicar o expresar de forma diferente algo que ya se ha expresado de otra forma")"15.

Para mí este intercambio entre Bachmaier, Engländer y Correa Robles indica, de por sí, la utilidad de haber propuesto la metáfora de la traducción legal en este contexto. No creo que la metáfora de la traducción no pueda ser criticada o no tenga sus propias limitaciones. El punto importante al proponerla fue resaltar mediante ella las transformaciones a que las ideas, normas e instituciones legales están sujetas cuando circulan entre distintos sistemas jurídicos, sea por decisiones de los redactores e intérpretes del sistema receptor o por diferencias estructurales entre los sistemas jurídicos.

La metáfora y puntos asociados con ella también han sido utilizados o discutidos no solo para analizar reformas procesales penales ${ }^{16}$, sino

12 Engländer, A., "Observaciones a 'De los transplantes legales a las traducciones legales:..' de Máximo Langer”, en este volumen de Dicusiones, sección 4.

${ }^{13}$ Correa Robles, C., op. cit. sección 10.

${ }^{14}$ Engländer, A., op. cit., sección 4.

${ }^{15}$ Ver Bachmaier, L., op. cit., primer párrafo de la sección 4.

16 Ver, por ejemplo, Ciocchini, P., op. cit., p. 32-33, sobre Provincia de Buenos Aires; Hans, V.P., “Trial by Jury: Story of a Legal Transplant", Law \& Society Review, 51(3), 2017, pp. 471-499. 
Quince años después: traducciones legales, globalización del plea bargaining...

también otros fenómenos como la difusión y recepción del concepto de desapariciones forzadas ${ }^{17}$, del derecho de asilo ${ }^{18}$, del certiorari de la Corte Suprema de Estados Unidos ${ }^{19}$, de conceptos de derecho constitucional alemán a Corea del $\operatorname{Sur}^{20}$, y del derecho impositivo ${ }^{21}$, para mencionar algunos ejemplos. La metáfora y puntos asociados con ella han sido utilizados no solo por abogados, juristas y sociólogos del derecho, sino también por investigadores de otras disciplinas tales como historiadores ${ }^{22}$ y politólogos de las relaciones internacionales ${ }^{23}$.

\section{Plea bargaining y modelos procesales}

Pasando a otro punto, una vez que el artículo expone su reconceptualización de los sistemas acusatorio e inquisitivo y propone la metáfora de la traducción legal, el artículo pasa a explicar por qué el plea bargaining puede ser aceptable en una concepción del proceso penal como una disputa entre dos partes. Dentro de esta concepción, si el imputado admite su culpabilidad, ya no hay una disputa entre las partes y el caso puede ser adjudicado sin juicio y en base a esa admisión de culpabilidad. En contraste, en el modelo de la investigación oficial el proceso penal es entendido como una investigación unitaria llevada a cabo por funcionarios públicos imparciales. Dentro de esta concepción, la admisión de culpabilidad del imputado

17 Dulitzky, A,E., “The Latin-American Flavor of Enforced Disappearances”, Chicago Journal of International Law 19 (2), 2019, pp. 423-489.

18 Ghezelbash, D., Refuge Law: Asylum Law in an Interdependent World, Cambridge University Press, 2018, pp. 5-6.

19 Barrera, L., "Gatekeeping: Documents, Legal Knowledge, and Judicial Authority in Contemporary Argentina”, PoLAR, 41 (1), 2018, pp. 90-107.

${ }^{20}$ Mosler, H.B., "Decoding the 'Free Democratic Basic Order' for the Unification of Korea", Korea Journal, 57 (2), 2017, pp. 5-34.

${ }^{21}$ Infanti, A.C., Our Selfish Tax Law: Toward Tax Reform that Mirrors Our Better Selves, Cambridge: Ma, The MIT Press, 2018, pp. 33-34.

${ }^{22}$ Ver, por ejemplo, Dueñas, A., "Indian Colonial Actors in the Lawmaking of the Spanish Empire in Peru”, Etnohistory, 65 (1), 2018, pp. 51-73.

${ }^{23}$ Ver, por ejemplo, Brake, B. y Katzenstein, P.J., "Lost in Translation? Nonstate Actors and the Transnational Movement of Procedural Law”, International Organization, 67 (4), 2013, pp. 725-757. 
puede ayudar a los funcionarios públicos imparciales a determinar la verdad material, pero la admisión de culpabilidad formal del imputado no puede disponer del proceso ${ }^{24}$.

Este análisis puede contribuir a explicar por qué mientras las jurisdicciones anglosajonas han utilizado mecanismos consensuales para llegar a condenas penales desde hace mucho tiempo, las jurisdicciones de la tradición continental europea y latinoamericana no adoptaron dichos mecanismos -al menos respecto de delitos de cierta gravedad- hasta décadas recientes. Pero esto no significa, como señala Correa Robles en su contribución ${ }^{25}$, que las jurisdicciones de tradición continental-europea y latinoamericana en donde todavía prevalece el sistema de la investigación oficial no puedan adoptar e incorporar estos mecanismos ${ }^{26}$. Ello es así por múltiples motivos.

En primer lugar, además de posibles influencias del proceso penal estadounidense, hay muchos otros posibles factores que pueden contribuir a explicar la adopción de mecanismos consensuales por distintas jurisdicciones, incluyendo jurisdicciones no anglosajonas, tales como la cantidad de casos que ingresan al sistema penal, la complejidad de ciertos casos, la protección de la víctima, la reducción del trabajo de jueces, fiscales y defensores, y otros factores o elementos ${ }^{27}$.

En segundo lugar, en ninguna jurisdicción prevalece de modo absoluto el modelo de la disputa o el modelo de la investigación. Toda jurisdicción es un híbrido y existen muchos híbridos diferentes. Con lo cual, aun las jurisdicciones en donde predomina el modelo de la investigación oficial han encontrado distintas maneras de incorporar mecanismos consensuales. Pero en la medida que estos mecanismos reflejan el modelo de la disputa, su adopción por parte de jurisdicciones en donde ha predominado

${ }^{24}$ Langer, M., "La Dicotomía Acusatorio-Inquisitivo y la Importación de Mecanismos Procesales de la Tradición Jurídica Anglo-Sajona", en Maier, J. y Bovino, A. (comps.), Procedimiento Abreviado, Buenos Aires, Ediciones del Puerto, 2001, p. 97-133; también publicado en Hendler, E.S. (comp.), Las Garantías Penales y Procesales Penales. Enfoque Histórico-Comparado, Buenos Aires, Editores del Puerto, 2001, p. 239.

${ }^{25}$ Correa Robles, C., op. cit., sección 8.

${ }^{26}$ Ver Correa Robles, op. cit., sección 8.

${ }^{27}$ Langer, M., "Plea Bargaining and the Global Administratization of Criminal Convictions", Annual Review of Criminology, 3, 2020, en prensa. 
Quince años después: traducciones legales, globalización del plea bargaining...

el modelo de la investigación oficial puede llevar a transformaciones en estas jurisdicciones como las que documenta el artículo que es objeto de este simposio.

\section{Los casos de estudio, dos puntos sobre Alemania y el modelo del juez-gerente basado en la cooperación}

Una vez articulado su marco conceptual y teórico, el artículo objeto de este simposio analiza cuatro casos de estudio: la adopción de distintos mecanismos consensuales de resolución de casos penales por parte de Alemania, Argentina, Francia e Italia. El artículo examina las diferencias entre estos mecanismos consensuales y el plea bargaining estadounidense y entre estos mecanismos conceptuales entre sí, así como el impacto que la adopción de estos mecanismos ha tenido y puede tener en el futuro sobre la concepción del proceso penal predominante en cada una de estas jurisdicciones.

Las contribuciones a este simposio no discuten, al menos mayormente, los casos de estudio argentino, francés e italiano ${ }^{28}$. Pero las contribuciones de Correa Robles y Engländer discuten el caso de estudio alemán. Querría entonces analizar aquí dos puntos que Engländer plantea en su contribución sobre este caso, uno crítico, otro positivo.

El primer punto es que Engländer cuestiona el uso del caso alemán como un ejemplo de americanización débil porque, como el artículo objeto de este simposio menciona expresamente, en el caso alemán la práctica parece haber surgido en los 1970s como una respuesta a necesidades concretas de dar respuesta al aumento de casos y a la complejidad de ciertos

${ }^{28}$ Otros trabajos han hecho uso de o se han referido al análisis de otros casos de estudio del artículo. Ver, por ejemplo, Colao, F., "Per una storia del processo penale 'all'Italiana.' 'Astratte Modellistiche' e 'Abitudini Profondamente Radicate”, en Meccarelli, M. y Solla Sastre, M.J. (comps.), Spatial and Temporal Dimensions for Legal History: Research Experiences and Itineraries, Max Planck Institute for European Legal History, 2016, pp. 241-278, pág. 263; Vriend, K., Avoiding a Full Criminal Trial, Springer, 2016, pág. 4; Quattrocolo, S., "Participatory Rights in Comparative Criminal Justice. Similarities and Divergences Within the Framework of the European Law", en Quattrocolo, S. y Ruggieri, S. (comps.), Personal Participation in Criminal Proceedings, Springer, 2019, pp. 449-509, nota 87. 
casos antes que como producto de profundas influencias culturales del sistema estadounidense. Engländer encuentra esta afirmación contradictoria con el propio concepto de traducción legal ya que, si la práctica posiblemente no surgió de influencias directas del sistema estadounidense, ¿como puede ser calificada como una traducción de ese sistema ${ }^{29}$ ?

El problema con esta crítica de Engländer es que asume una visión empobrecedora, simplista y reduccionista de los conceptos y fenómenos de influencia, americanización y traducción legal. En primer lugar, estos conceptos no implican que para que una cierta reforma sea un ejemplo de influencia estadounidense o de cualquier otro sistema, esta influencia sea la única causa o la causa principal que ha llevado a la adopción de una reforma. Por ejemplo, puede que causas como el aumento en el número de casos o la complejidad de los casos que ingresan al sistema penal abran lo que John Kingdon llama "ventanas de oportunidad para políticas públicas", es decir, situaciones en las que se abre una oportunidad para proponer e introducir reformas. Y que una vez que se abren estas ventanas de oportunidad, la influencia de un sistema o la creencia en una cierta reforma pueda ser utilizada para realizar una propuesta y aprovechar esta ventana de oportunidad. Por ejemplo, la transición a la democracia y la percepción de que la comisión de delitos había aumentado abrió ventanas de oportunidad para reformas a la administración de justicia penal en América Latina desde los 1990s y un grupo de reformadores aprovechó esas ventanas de oportunidad para proponer reformas acusatorias que incluyeron el procedimiento abreviado como posible respuesta a esos problemas ${ }^{30}$.

En segundo lugar, los fenómenos de influencia y traducción legal incluyen no solo escenarios en los que un texto legal foráneo es usado como base para redactar un texto legal en el sistema receptor como parece

${ }^{29}$ Engländer, A., op. cit., sección 3.

${ }^{30}$ Langer, M., "Revolución en el proceso penal latinoamericano: difusión de ideas legales desde la periferia", CEJA, 2008; republicado en Revista de Derecho Procesal Penal.-Número Extraordinario. El Proceso Penal Adversarial, 2, 2009, pág. 53; en Revista Derecho Penal Mínimo, 4, 2010, pág. 23; y en Kostenwein, E. (comp.), Sociología de la Justicia Penal, Ediar, 2017. Este artículo fue originalmente publicado en inglés como "Revolution in Latin American Criminal Procedure: Diffusion of Legal Ideas from the Perifery", American Journal of Comparative Law 55, 2007, pág. 617. 
Quince años después: traducciones legales, globalización del plea bargaining...

asumir Engländer, sino que también incluye otros escenarios en los que la influencia legal de otro sistema puede ocurrir mediante otros canales. Por ejemplo, los redactores de reformas en un sistema pueden inspirarse en ideas, normas e instituciones legales de otro sistema sin tomar ningún texto particular de ese otro sistema, sino basándose en descripciones más generales de esa idea, norma o institución incluidas en descripciones doctrinarias locales o extranjeras. $\mathrm{O}$, por ejemplo, cuando abogados de un país estudian en el exterior pueden ser influenciados por el sistema al que han ido a estudiar y pueden intentar adaptar ideas de ese sistema a su sistema nacional una vez que retornan a su país de origen sin necesariamente utilizar ningún texto o regulación particular de ese sistema como modelo. $\mathrm{O}$, por ejemplo, la influencia de un sistema puede ocurrir mediante canales no jurídicos, como representaciones de un cierto sistema legal en series de televisión, películas, libros y otros artefactos culturales.

Sería entonces empobrecedor, simplista y reduccionista limitar los casos de influencia solo a situaciones en donde un texto legal extranjero es utilizado como base para una reforma en otra jurisdicción. En el caso alemán, hay elementos que indican que quienes introdujeron los entendimientos o acuerdos no se basaron en regulaciones legales estadounidenses del plea bargaining, entre otros motivos porque los jueces, abogados y fiscales alemanes inicialmente introdujeron la práctica informalmente y en secreto, y no mediante un texto legal. Pero dado que la práctica fue introducida en secreto, no ha sido posible saber si hubo otros canales de influencia estadounidense cuando la práctica fue introducida, presumiblemente en los años 70. Lo que sí es claro es que desde el primer momento que la existencia de la práctica se hizo pública, el plea bargaining estadounidense ha estado presente como una referencia en la materia. De hecho, como explico en el artículo objeto de este simposio, el abogado que hizo pública por primera vez la existencia de la práctica de los acuerdos en 1982 utilizó el seudónimo "Deal” en clara referencia al término en inglés para “acuerdo" 31 . Y ya desde los años 80 en adelante, distintos doctrinarios ale-

31 Detlef Deal, “Der strafprozessuale Vergleich”, StV, 2, 1982, pág. 545. 
manes realizaron múltiples referencias al plea bargaining estadounidense y a la doctrina y jurisprudencia estadounidense sobre el tema ${ }^{32}$.

Finalmente, es también importante notar que el análisis comparado basado en la reconceptualización de los sistemas acusatorio e inquisitivo y la herramienta heurística de la traducción legal ofrecidas en el artículo objeto de este simposio pueden ser utilizados fructíferamente aun en casos en los que no hay influencias directas entre dos sistemas jurídicos. Por ejemplo, incluso si la práctica alemana no hubiera tenido ninguna de las influencias estadounidenses mencionadas en el párrafo anterior, uno podría utilizar los conceptos de estructuras de interpretación y sentido, disposiciones internas y la dimensión de poderes procesales para explicar las diferencias entre los mecanismos consensuales de resolución de casos adoptados en Alemania y en Estados Unidos, y asumir que Alemania ha traducido a su propio sistema procesal de producción de sentido esta ten-

${ }^{32}$ Ver, por ejemplo, Hassemer, R. y Hipper, G., "Informelle Absprachen in der Praxis des deutschen Strafverfahrens", StV, 8, 1986, pág. 360; Hanack, E.-W., "Vereinbarungen im Strafprozeß, ein besseres Mittel zur Bewältigung von Großverfahren?”, StV, 11, 1987, pág. 500501; Cramer, P., "Absprachen im Strafprozeß”, Festschrift für Kurt Rebmann, C.H. Beck'sche, 1989, pág. 145, 153-159 (comparando la confesión en Alemania con el guilty plea estadounidense y mencionando el reconocimiento del plea bargaining por la Corte Suprema de Estados Unidos); Lüdemann, C. y Bußmannm, K.-D., “Diversionchancen der Mächtigen? Eine empirische Studie über Absprachen im Strafprozeß”, Kriminologisches Journal 21, 1989, pág. 54, (citando trabajos de Malcolm Feeley y Milton Heumann); Schünemann, B., Absprachen im Strafverfahren? Grundlagen, Gegenstände und Grenzen. Gutachten B. zum 58 Juristentag, C.H. Beck, 1990 (ver, por ejemplo, pág. 11, señalando las importantes líneas de conexión con el procedimiento estadounidense); Weigend, T., Absprachen in ausländischen Strafverfahren: Eine rechtsvergleichende Untersuchung zu konsensualen Elementen im Strafprozeß, Max-Planck-Institut für Ausländisches und internationales Strafrecht, 1990; Schünemann, B., “ ¿Crisis del Procedimiento Penal? (¿Marcha triunfal del procedimiento penal americano en el mundo?)", Cuadernos de Doctrina y Jurisprudencia Penal, 8, Silvina Bacigalupo trad., 1998, pág. 417; Siolek, W., Verständigung in der Hauptverhandlung, Nomos, 1993, pp. 227-232; Stuckenberg, C.-F., "\$257c", en Volker, E. et al (comps.), Löwe-Rosenberg Die Strafprozeßordnung und das Gerichtsverfassungsgesetz, 6, 26 ed., De Gruyter, 2013, pág. 53 (incluyendo literatura estadounidense sobre el plea bargaining y realizando comparaciones con Estados Unidos); Stuckenberg, C.F., "Zur Verfassungsmäßigkeit der Verständigung im Strafverfahren”, ZIS 4, 2013, pág. 218. También ha habido referencias al plea bargaining y al proceso penal estadounidense en casos penales. Ver, por ejemplo, Bundesgerichtshof, Urt. v. 28.08.1997, Az.: 4 StR 240/97, II. a). aa), disponible en https:// www.jurion.de/urteile/bgh/1997-08-28/4-str-240_97/. 
Quince años después: traducciones legales, globalización del plea bargaining...

dencia global hacia la adopción de mecanismos consensuales originada (al menos parcialmente) en los Estados Unidos, sin conciencia de su origen. Para el comparativista, sería de cualquier modo relevante analizar las diferencias de regulación entre mecanismos consensuales en diferentes jurisdicciones, explicar las razones y la relevancia de estas diferencias, y dar cuenta de procesos globales de difusión de ideas, normas e instituciones legales y de sus orígenes.

El segundo punto que Engländer analiza respecto del caso alemán se refiere al modelo del juez-gerente basado en la cooperación que, como ya expliqué, también articulé como otra contribución independiente en el trabajo objeto de este simposio. Mi argumento en este sentido fue que la práctica de los acuerdos coloca al proceso penal alemán en una encrucijada o tensión entre dos modelos procesales. Por un lado, si los acuerdos son utilizados por el tribunal para investigar lo ocurrido, los acuerdos pueden ser compatibles con el sistema inquisitivo o modelo de la investigación oficial alemán en la medida en que, bajo ellos, el tribunal todavía sería un investigador activo de la verdad material. Pero si los acuerdos son en cambio utilizados para dar una respuesta rápida a los casos penales en desmedro de asegurar la correspondencia entre las condenas penales y la verdad material de lo ocurrido, los acuerdos estarían moviendo al proceso penal alemán en la dirección del modelo del juez-gerente basado en la cooperación.

En su contribución para este número de Discusiones, Engländer utiliza esta oposición entre estos dos modelos para argumentar que mientras que en la regulación legislativa, el Tribunal Constitucional alemán y decisiones del Tribunal Supremo Federal alemán requieren que el tribunal respete su deber de establecer la verdad material de lo ocurrido aun cuando los casos son resueltos mediante acuerdos, la práctica de los tribunales y la propia concepción de su rol por parte de los jueces alemanes sugieren que un buen número de estos tribunales y jueces enfatizan en cambio dar una rápida resolución a los casos en consonancia con el modelo del juez-gerente basado en la cooperación ${ }^{33}$. El hecho de que Engländer considere que este modelo es útil para analizar prácticas actuales en el proceso penal alemán es una

${ }^{33}$ Engländer, A., op. cit., sección 2 y primer párrafo de la sección 3. 
indicación de la vigencia también de esta herramienta teórica y análisis que realicé en su momento.

Esta herramienta teórica que desarrollé en más detalle en mi trabajo posterior $^{34}$, también ha sido utilizada para, por ejemplo, comparar y discutir el rol del juez en plea bargaining y otros mecanismos consensuales en Alemania, Connecticut y Florida ${ }^{35}$, y para analizar el procedimiento penal de, entre otras jurisdicciones, los tribunales penales internacionales ${ }^{36} \mathrm{y}$ de Inglaterra $^{37}$.

\section{Conclusión}

Este artículo ha discutido las principales contribuciones y la actualidad del trabajo que ha sido objeto de este número de Discusiones. Plea bargaining $\mathrm{y}$ otros mecanismos consensuales se han diseminado por distintas jurisdicciones del globo que antes no contaban con dichos mecanismos. En muchas jurisdicciones, esta difusión ha sido influenciada por el plea bargaining estadounidense y ha venido de la mano de un avance del modelo de la disputa que predomina como concepción del proceso penal en Estados Unidos.

Pero esta tendencia no ha resultado en una copia o adopción literal del plea bargaining estadounidense o en el predominio del modelo de la disputa como concepción del proceso penal en las jurisdicciones continentales europeas y latinoamericanas. Ello es así, entre otras razones, porque el plea bargaining ha sido transformado al ser adoptado por estas jurisdiccio-

${ }^{34}$ En mi trabajo posterior, desarrollé en detalle este modelo y me referí a él como "managerial judging", tomando la expresión popularizada por Judith Resnik, aunque desarrollando este modelo de un modo sustancialmente diferente a como Resnik lo había conceptualizado. Ver Langer, M., "The Rise of Managerial Judging”, op. cit.

35 Turner, J., "Judicial Participation in Plea Negotiations: A Comparative View", American Journal of Comparative Law, 54 (1), 2006, pp. 199-267.

${ }^{36}$ Combs, N.A., "Legitimatizing International Criminal Justice: The Importance of Process Control”, Michigan Journal of International Law, 33 (2), 2012, pp. 321-381; Jackson, J.D. y Summers, S. J., op. cit., pág. 124-131; Langer, M., “The Rise of Managerial Judging”, op. cit.; Vasiliev, S., International criminal trials: a normative theory, University of Amsterdam, 2014.

${ }^{37}$ McEwan, J., "From adversarialism to managerialism: criminal justice in transition", Legal Studies, 31 (4), 2011, pp. 519-546. 
Quince años después: traducciones legales, globalización del plea bargaining...

nes ya sea por decisiones de los reformadores que redactaron y adoptaron los mecanismos consensuales, por sus usuarios, o por diferencias entre el sistema legal estadounidense y los sistemas continentales europeos y latinoamericanos.

En lugar de producir una americanización en sentido fuerte, la influencia del plea bargaining estadounidense y del proceso penal estadounidense más en general ha contribuido a una fragmentación de la tradición continental europea y latinoamericana. Hasta hace poco, las jurisdicciones de esta tradición predominantemente concebían el proceso penal como una investigación oficial única llevada a cabo por funcionarios públicos imparciales. Esta concepción todavía predomina en un buen número de estas jurisdicciones, pero en otras jurisdicciones otras concepciones del proceso penal, tales como el modelo de la disputa y el modelo del juez-gerente basado en la cooperación, han avanzado en distintos grados.

Hay muchos otros posibles temas para analizar sobre la difusión del plea bargaining y otros mecanismos consensuales de resolución de casos penales $^{38}$. Pero los temas discutidos en el artículo objeto de este volumen tales como la globalización del derecho, la tesis de la americanización, los fenómenos de influencia, difusión y traducción, la interpretación jurídica, los fenómenos de permanencia y cambio en la administración de justicia, y distintas concepciones del proceso penal son importantes. Las distintas contribuciones de "De los trasplantes legales a las traducciones legales..." mantienen su actualidad para analizarlos respecto no solo del plea bargaining y otros mecanismos consensuales, sino también de otros fenómenos relacionados con el proceso penal y otros campos del derecho.

${ }^{38}$ Yo mismo he analizado otros aspectos de este fenómeno. Ver Langer, M., "Plea Bargaining and the Global Administratization of Criminal Convictions", op. cit.; y Langer, M., "Rethinking Plea Bargaining: The Practice and Reform of Prosecutorial Adjudication in American Criminal Procedure", American Journal of Criminal Justice 33, 2006, pág. 223. 
Máximo Langer

\section{Bibliografía}

Armenta Deu, T., Sistemas procesales penales: La justicia penal en Europa y América, Madrid, Marcial Pons, 2012.

Bachmaier, L. "La no-americanización del proceso penal continental europeo: Del trasplante a la traducción jurídica en Langer" en este volumen de Discusiones.

Barrera, L., "Gatekeeping: Documents, Legal Knowledge, and Judicial Authority in Contemporary Argentina", PoLAR, 41 (1), 2018, pp. 90-107.

Brake, B. y Katzenstein, P.J., "Lost in Translation? Nonstate Actors and the Transnational Movement of Procedural Law", International Organization, 67 (4), 2013, pp. 725-757.

Ciocchini, P., "Reformers' unfulfilled promises: accountability deficits in Argentinean criminal courts", International Journal of Law in Context, 14 (1), 2018, pp. 22-42.

Colao, F., "Per una storia del processo penale 'all'Italiana'. 'Astratte Modellistiche' e 'Abitudini Profondamente Radicate', en Meccarelli, M. y Solla Sastre, M.J. (comps.), Spatial and Temporal Dimensions for Legal History: Research Experiences and Itineraries, Max Planck Institute for European Legal History, 2016, pp. 241-278.

Combs, N.A., "Legitimatizing International Criminal Justice: The Importance of Process Control", Michigan Journal of International Law, 33 (2), 2012, pp. 321-381.

Correa Robles, C., "Mecanismos negociados de resolución de conflictos penales en Chile y Alemania -Una aproximación pragmática”, en este volumen de Discusiones.

Cramer, P., “Absprachen im Strafprozeß”, Festschrift für Kurt Rebmann, C.H. Beck’sche, 1989, pág. 145.

Detlef Deal, “Der strafprozessuale Vergleich”, StV, 2, 1982, pág. 545.

Dueñas, A., "Indian Colonial Actors in the Lawmaking of the Spanish Empire in Peru", Etnohistory, 65 (1), 2018, pp. 51-73.

Dulitzky, A,E., "The Latin-American Flavor of Enforced Disappearances", Chicago Journal of International Law 19 (2), 2019, pp. 423-489.

Engländer, A., "Observaciones a 'De los transplantes legales a las traducciones legales:..' de Máximo Langer”, en este volumen de Dicusiones. 
Quince años después: traducciones legales, globalización del plea bargaining...

Ghezelbash, D., Refuge Law: Asylum Law in an Interdependent World, Cambridge University Press, 2018.

Hanack, E.-W., "Vereinbarungen im Strafprozeß, ein besseres Mittel zur Bewältigung von Großverfahren?”, StV, 11, 1987, pág. 500.

Hans, V.P., "Trial by Jury: Story of a Legal Transplant”, Law \& Society Review, 51(3), 2017, pp. 471-499.

Hassemer, R. y Hipper, G., "Informelle Absprachen in der Praxis des deutschen Strafverfahrens”, StV, 8, 1986, pág. 360.

Infanti, A.C., Our Selfish Tax Law: Toward Tax Reform that Mirrors Our Better Selves, Cambridge:Ma, The MIT Press, 2018.

Jackson, J.D. y Summers, S. J., The Internationalisation of Criminal Evidence: Beyond the Common Law and Civil Law Traditions, Cambridge University Press, 2012.

Langer, M., "La Dicotomía Acusatorio-Inquisitivo y la Importación de Mecanismos Procesales de la Tradición Jurídica Anglo-Sajona”, en Maier, J. y Bovino, A. (comps.), Procedimiento Abreviado, Buenos Aires, Ediciones del Puerto, 2001, p. 97-133.

Langer, M., "Plea Bargaining and the Global Administratization of Criminal Convictions", Annual Review of Criminology, 3, 2020, en prensa.

Langer, M., "Rethinking Plea Bargaining: The Practice and Reform of Prosecutorial Adjudication in American Criminal Procedure", American Journal of Criminal Justice 33, 2006, pág. 223.

Langer, M., "Revolución en el proceso penal latinoamericano: difusión de ideas legales desde la periferia", CEJA, 2008.

Langer, M., "The Rise of Managerial Judging in International Criminal Law", American Journal of Comparative Law, 53 (4), 2005, pp. 835-909.

Lüdemann, C. y Bußmannm, K.-D., "Diversionchancen der Mächtigen? Eine empirische Studie über Absprachen im Strafprozeß”, Kriminologisches Journal 21, 1989, pág. 54.

McEwan, J., "From adversarialism to managerialism: criminal justice in transition", Legal Studies, 31 (4), 2011, pp. 519-546.

Montana, R., "Procedural tradition in the Italian Criminal Justice System: The Semi-adversarial Reform in 1989 and the inquisitorial cultural resistance to adversarial principles", The International Journal of Evidence \& Proof, 20 (4), 2016, pp. 289-304. 
Máximo Langer

Mosler, H.B., "Decoding the 'Free Democratic Basic Order' for the Unification of Korea”, Korea Journal, 57 (2), 2017, pp. 5-34.

Quattrocolo, S., "Participatory Rights in Comparative Criminal Justice. Similarities and Divergences Within the Framework of the European Law", en Quattrocolo, S. y Ruggieri, S. (comps.), Personal Participation in Criminal Proceedings, Springer, 2019, pp. 449-509.

Roach, K., "Wrongful Convictions: Adversarial and Inquisitorial Themes", N.C.J. Int'l L. \& Com. Reg., 35 (2), 2010, pp. 387-446.

Schünemann, B., “ ¿Crisis del Procedimiento Penal? (¿Marcha triunfal del procedimiento penal americano en el mundo?)", Cuadernos de Doctrina y Jurisprudencia Penal, 8, Silvina Bacigalupo trad., 1998, pág. 417.

Schünemann, B., Absprachen im Strafverfahren? Grundlagen, Gegenstände und Grenzen. Gutachten B. zum 58 Juristentag, C.H. Beck, 1990.

Siolek, W., Verständigung in der Hauptverhandlung, Nomos, 1993, pp. 227232.

Sklansky, D., “Anti-Inquisitorialism”, Harvard Law Review, 112, 2009, pp.1634-1704.

Stuckenberg, C.-F., “\$257c", en Volker, E. et al (comps.), Löwe-Rosenberg Die Strafprozeßordnung und das Gerichtsverfassungsgesetz, 6, 26 ed., De Gruyter, 2013, pág. 53.

Stuckenberg, C.F., “Zur Verfassungsmäßigkeit der Verständigung im Strafverfahren”, ZIS, 4, 2013, pág. 218.

Turner, J., "Judicial Participation in Plea Negotiations: A Comparative View", American Journal of Comparative Law, 54 (1), 2006, pp. 199-267.

Vasiliev, S., International criminal trials: a normative theory, University of Amsterdam, 2014.

Vriend, K., Avoiding a Full Criminal Trial, Springer, 2016.

Weigend, T., Absprachen in ausländischen Strafverfahren: Eine rechtsvergleichende Untersuchung zu konsensualen Elementen im Strafprozeß, Max-Planck-Institut für Ausländisches und internationales Strafrecht, 1990. 